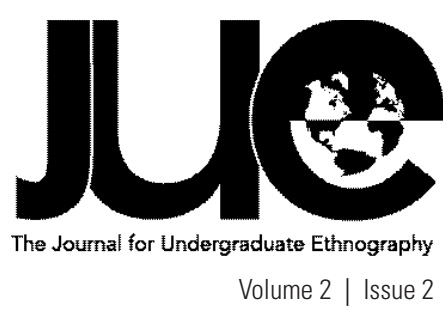

\title{
Jainism's Intersection with Contemporary Ethical Movements: An Ethnographic Examination of a Diaspora Jain Community
}

\section{Brett Evans}

Elon University, bevans8@elon.edu

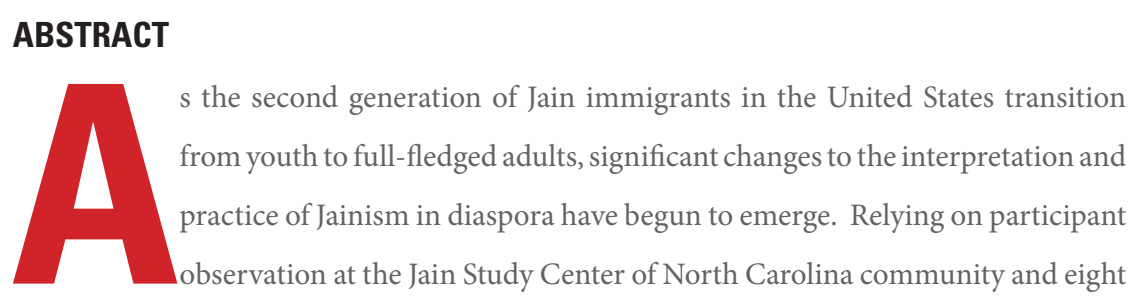
interviews with members of this community, my research investigates the critical shift present between the younger generation and the older generation of this population and examines its potential causes. I argue that the absence of religious authority in diaspora and the increase of Western influence have redirected emphasis from ritual to ethical practice, particularly within the younger generation. This increased focus on ethical practice has presented itself through the incorporation of elements from contemporary Western environmental and animal rights movements. Additionally, it has increased the prominence of the core Jain values of ahimsa (non-violence), aparigraha (nonattachment or non-possessiveness), and anekantavada (non-one-sidedness), as well as their corresponding day-to-day actions, at the expense of traditional ritual practices such as puja (worship).

Keywords: Jainism, Diaspora, Religion, Environmentalism, Veganism 
AAVE BEEN HERE IN THIS COUNTRY FOR THE LAST 42 YEARS. I WAS BORN AND RAISED IN INDIA. I got married at the age of 23, and then I came here. So, I have lived more here than in India. Of course, in Ifdia, I am Jain. I go to the temple; I worship the god, [Mahavira]; don't eat these things [-animals, eggs, root and many-seeded vegetables, honey, alcohol]; get in by dark; eat before sunset. Those things - the rituals - I knew them. But what is Jainism? Who is arhat ${ }^{\text {? }}$ Who is siddha ${ }^{2}$ ? I had no idea. The prayer we do every day, I used to do it when I was five years old - when I was very little, okay? And, everybody is supposed to know that 'hey, you started eating, first pray god'. So, I was doing it, but I didn't know what it means. Maybe, at that time, I was not mature enough; I was too young. But, here [in the United States], I started putting two and two together. I learned so many things after coming here to this country... So, in that way, yes, it is better here. But, I am missing so many things in India that I am not getting here: some moral support; some motivation; if he, [my husband], doesn't do it, suppose then my sister is there, or my sister-in-law, or mother-in-law, suppose today they are fasting or they are going to perform some ceremony. I say ' $\mathrm{Oh}$, you are doing [that]? Let me do it also'... In the initial stage, you need support, or company, or motivation. We get it over there [in India]. Here, no. We don't get it. Once a month, we go [to the temple], pray together, [and say], 'Hi. How are you doing? Goodbye.' That is not motivation. But, remember one thing: religion is not in a group. A person should be doing by himself or herself. It is not a group activity, but in this initial stage, we need company, because we have not reached to that stage where we don't need anybody. [Eventually], we have to do that. - Arati $\left(\right.$ Interview, 2010) ${ }^{3}$ 


\section{INTRODUCTION}

On opposite couches in Arati's living room, we drank delicious, homemade chai tea. This was not the chai tea that I was used to encountering: this was made with spices from India and soy milk. It had a rich flavor, stronger than any I had tried before. More importantly for me, I did not need to question the ingredients, because a vegan made it. This home felt like a sanctuary for me. I was with others who shared some of my most important and personal beliefs and practices. For a little while, while I conducted this interview, I could remain among like-minded friends.

As an individual who strongly believes in non-violence, similar to that which is espoused by core Jain doctrines ${ }^{4}$, I found it easy to empathize with Arati's experiences of insufficient community and desire for external support. Just as runners spur each other on in a physical race, community members spur spiritual progression in their fellows. I would soon leave her home, ending our companionship and forcing me to become the outsider again. In this same way, Arati felt that the monthly meetings of the Jain Study Center of North Carolina (JSCNC) were brief and far too infrequent, leaving her once again as an outsider each time one ended. These gatherings were no replacement for the community she had left behind many years ago in India.

In coming to the United States, immigrant Jains left behind more than friends, family, and other lay members: these individuals were also unable to take their monks and nuns with them. These honored and respected religious leaders, who have renounced their worldly possessions and dedicated their lives to their practices, are largely absent in diaspora. ${ }^{5}$ Due to monastic vows which restrict their ability to travel, very few monks and nuns are willing to journey abroad. Monastics serve as the tradition's primary exemplars, who all other Jains strive to emulate. Moreover, much of Jainism as it exists in India is centered on these leaders, with the lay population worshipping and supporting the sacred lives and dedication of ascetics (Babb 1996). Lay Jains in diaspora are cut off from these role models and their teachings, which effectively creates a significant gap in religious authority and ritual practice. Drawing upon ethnographic fieldwork and scholarly literature, this paper demonstrates ways in which American Jains have sought to fill this gap with decentralized lay leadership and lay agendas that shift community focus from renunciation and traditional practices to ethical and social actions, particularly those associated with contemporary environmental and animal rights movements. 


\section{LOCATION, COMIMUNITY, AND PARTICIPANTS}

As I first attempted to assess the feasibility of an ethnographic project which would investigate diaspora Jainism's relationship with contemporary environmental and animal rights philosophies, I was relieved to locate a Jain community an hour's driving distance from my university. This community is centered in Cary, North Carolina, a wealthy, residential suburb of Raleigh. Situated in the middle of what is known as the Research Triangle (Raleigh, Durham, and Chapel Hill), a region which is notable for its high concentration of universities and engineering and technology firms, it has a sizable South Asian immigrant population, including a number of Jains. Many more Jains live in the surrounding region, enough to justify the creation of a formal Jain community-the JSCNC. Though this community has several hundred members, an average of 50 attends the scheduled monthly meetings. Due to its membership size, among other factors, it has chosen to share temple space with Cary's Hindu Society of North Carolina, rather than purchase its own building. While not a sectarian organization, the JSCNC's membership is predominantly of Svetambara lineage, which is the majority sect of Jainism.
In order to contextualize the narratives they presented, some background about my research participants is necessary. All of them were middle- to upper-class individuals living within the Research Triangle. While I attempted to achieve gender balance among those I interviewed, I managed to secure interviews with only two females out of eight total participants. I believe because I am a male undergraduate student, female community members were less willing to interact with me outside of meetings than males. This disparity is unfortunate. Yet, due to time constraints, it was unavoidable. Of the six participants born in India, all were originally from North India, most commonly Gujarat, and they immigrated for education and employment opportunities. As the table below demonstrates, the majority of those I interviewed were working in medical, engineering, and business fields, and most of adults were well educated, with graduate degrees as the norm. Three of the adults who participated in this research were actively involved with JSCNC as members of its executive committee.

\section{Research Participants:}

\begin{tabular}{|l|l|l|l|}
\hline Name & Estimated Age & Occupation & Country of Birth \\
\hline Nirmal & Mid 20s & Graduate Student & USA \\
\hline Pranav & Mid 20s & Graduate Student & USA \\
\hline Piyush & Early 40s & Engineer & India \\
\hline Sujash & Early 40s & Engineer & India \\
\hline Rajmati & Mid 40s & Homemaker & India \\
\hline Suchit & Mid 50s & Business Consultant & India \\
\hline Purav & Late 60s & Engineer & India \\
\hline Arati & Early 70s & Homemaker & India \\
\hline
\end{tabular}




\section{METHODS}

Initial contact with the JSCNC was made in August, 2010, through email correspondence with the respected lay Jain scholar Pravin Shah, a leader of both this community and national North American Jain organizations. Pravin and I arranged to meet at his home to discuss my research, and he generously agreed to introduce me to the JSCNC community and invited me to observe their monthly meetings, which take place at the Hindu Society of North Carolina in Cary. His introduction was important in that it established my role and purpose within the community, resulting in warm acceptance and offers of assistance and participation from its members.

I observed one annual retreat held in a local National Park that consisted of a mix of lectures and socializing; two monthly meetings which included lectures, puja (worship), and pathshalas (youth educational program); and I completed eight interviews. These interviews took place in a variety of locations, at the participant's discretion, including public spaces, libraries, and homes, and were an average of one hour in duration. Each interview was loosely based around a prepared set of questions, but the conversation was intentionally organic and not rigidly focused. To ensure anonymity, participants' names have been replaced with pseudonyms in this paper. Specific requests for interviews were made privately, through email and phone, and I did not inform participants and other community members of who else had been or would be interviewed. While eight formal interviews is a small sample of a community numbering in the low hundreds and therefore may be claimed to have limited utility, I argue that the depth possible in this sample size was more valuable than breadth.

\section{ARGUMENTS}

It is a mistake to view any religious tradition as static or uniform. Traditional practices and beliefs are always confronted with the challenge of adapting to or rejecting contemporary pressures. Religious practitioners often do not agree on which response should be given to this challenge, leading to disagreements and divides, even within indigenous contexts. One of Jainism's most evident splits is found between its two major sects Svetambara and Digambara. While each group differs in many notable ways, the sectarian names themselves attempt to distinguish each group from the other by indicating differing beliefs about acceptable monastic dress. Svetambaras (literally, "white-clad") allow monastics to wear simple cotton dress, while Digambaras (literally, "sky-clad") maintain that male monastics should be nude (Jaini 1991, xix). Beyond these differing interpretations of monastic dress, there are many other articulated and prominent divisions among Jains. One such further example can be found in the opposed Jain categories of Sthanakvasis-those who believe that constructing temples involves unacceptable violence and do not worship images (murtis) - and Deravasis-those who find temples acceptable to construct and use and do worship images (Cort 1991, 652).

In orthodox Jainism, the ultimate goal is to remove oneself from the world of violence and suffering by achieving liberation (moksha) of one's soul from the cycle of rebirth (samsara). One's mere existence in the world causes violence-from inhaling microscopic particles in the air to eating plants-and it is, therefore, a Jain's priority to mitigate this violence to the best of his or her ability. Practicing ahimsa (non-violence) is the preeminent path for mitigating the violence of worldly existence. Andrea Jain and Jeffrey Kripal note that "[orthodox] Jain ideology is... nonethical, in that the practices it requires of the adept are meant to remove him from structures that render social ethics of any sort possible" (Jain and Kripal 2009, 200). Seen in this way, ahimsa is not done so much out of compassion, but rather out of a desire to remove oneself from implication in worldly violence. Tracing this logic to its conclusion, a small number of Jains, both lay people and monastics, commit themselves to fasting to death (sallekanah) in an attempt at ultimate renunciation (Laidlaw 2005, 181).

Yet, as religions move into new geographic and cultural spaces, different interpretations, emphases, and enactments are common. In her essay From "Liberation to Ecology," Anne Vallely argues that in contemporary diaspora Jainism there is currently a "shift in ethical consideration away from a traditional orthodox liberation-centric ethos to a sociocentric or 'ecological' one" (Vallely 2002, 193). In other words, the inward focus that has long characterized the Jain tradition has recently begun to yield to an outward, social perspective, particularly in the diaspora. The growing understanding among diaspora Jains of ahimsa as an ethical priority, rather than a renunciatory tactic, is one important way in which this can be seen. Furthermore, the decentering of the traditional focus on achieving moksha is particularly noteworthy.

My participants were unanimous in emphasizing, in much detail and often unprompted, this great shift which is occurring in diaspora communities between the first generation of Indian Jain immigrants and the second. The ramifications of such a change in understanding and practice are quite profound. This shift may 
well be of the same magnitude as the divides concerning monastic dress, temple-building, and image worship that are previously mentioned. It is my contention that as sources of religious authority declined and Western influence increased in diaspora, the emphases on removing oneself from the world and utilizing traditional ritual practices have diminished, while the concepts of non-violence, non-attachment (aparigraha), and non-one-sidedness (anekantavada) have taken on a central and ethical role which draws elements not only from within the Jain traditions but also from other contemporary ethical movements, especially those relating to the environment and animals.

\section{LOSS OF RELIGIOUS AND TRADITIONAL AUTHORITY}

Whether or not there are Jain monks and nuns outside of India depends on who is asked. Some maintain the traditional view that, because of specific monastic vows relating to the violence entailed by travel, there can be no monks and nuns outside of India; these individuals view anyone who was a monk or nun in India as merely a scholar once they have traveled to the United States (Dundas 1992, 224). Others do not see the issue so decisively, and they are grateful for whatever spiritual leadership they are able to access outside of India. Piyush, as well as others I interviewed, saw intention as the key factor in his willingness to accept monks and nuns who travel. He argued that, "They come here-it is not for their benefit but for the benefit of others; so I still believe that they are monks and nuns because they have devoted their lives." Yet, he did clarify that he still did not think they were "completely" monks and nuns, because they have to live in houses and practice differently than they would in India. These views suggest that the quasi-monastics who travel beyond India lose a measure of authority and status. Because of this, even those rare monks and nuns who come to the United States cannot fill the same role they served traditionally in India.

Of those who were born in India, multiple participants described the experience of going to temple every morning in their home contexts. These temples were within walking distance from their homes, and monks and nuns were very much present in the lives of lay Jains who regularly visited these religious sites. James Laidlaw writes that in India "virtually all forms of lay religious practice are enactments of lay Jains' relationships with [monks and nuns]_praising and venerating renouncers, receiving blessings from them, hearing their sermons..." (Laidlaw 2010, 62). These ascetics played the roles of leaders, educators, and role models. In the United States, these crucial forms of lay Jain practice are no longer possible, leaving American Jains in search of replacements.

Due in part to the decreased importance and occurrence of meetings and in part to the small community sizes, many American Jain communities have chosen to share space with larger Hindu temples (Long 2009, 27). This results in not only the sharing of physical locations, but in the sharing of community. All participants told me that the increased size of the community focused around shared culture was very important to them and that they saw it in an overall positive light. This experience of a meshed community can result in the sharing of practices. Many Jains with whom I spoke had performed puja honoring a Hindu deity and did not see this as conflicting with their own beliefs. In this context, where practices and community are shared between Hindus and Jains, traditional Jain sectarian divides also seemed to be muted. Dogmatic differences were unimportant to every participant. As mentioned above, the JSCNC community is predominantly Svetambara, which is the majority Jain sect and includes 80 percent of all Jains worldwide. However, no participant classified him or herself as Svetambara in practice. In fact, several participants specifically qualified their answers regarding which sect they belonged to. A woman named Rajmati, for example, hesitated before saying "I belong to the Svetambara sect, but I don't like to differentiate." This loss of significance formerly associated with sects seems to further delineate American Jainism from historical power structures in India. The sectarian leadership and politics that the first-generation remembers well from their youth in India are notably absent in the United States.

The insufficient number of monks, nuns, and dedicated Jain temples has not only allowed for a more independent and self-led Jain laity, but also has prevented Jain youth from aspiring to join a monastic order. No participant was aware of any Jain who had become a monk or a nun in the United States. Rajmati told me that she had heard of a boy in Michigan who had "always wanted to go to the monks and nuns and listen to them more," so his parents decided to move back to India. In the United States, there are few ascetic role models and no structure in place for lay Jains to train to become monks or nuns. The absence of these models undergirds a diaspora shift from the old model of ritual practice towards a new one that includes a diminished role for ascetics.

This move away from traditional rituals is a watershed moment with regard to the shift of religious authority in diaspora Jainism. However, the power vacuum left behind by the ascetics 
has not remained indefinitely. Lay leaders have assumed some of the monks' and nuns' roles. These leaders maintain the community, organize events and meetings, and ensure that the youths' Jain education is not left solely to their parents. In some cases, they attempt to prevent the loss of traditional practices by translating valued rituals and performances into English and providing needed context. They often see their leadership as a temporary solution that will carry the diaspora communities to a more permanent one. One older lay leader, Purav, asserted that a permanent solution would be to establish a new monastic system that could work effectively and appropriately in diaspora contexts. He explained, "It will happen slowly...The religion is not going to die, okay? But it is not going to be the same way that we practiced it in India. It is going to be totally distinct, in its own form for America." Purav did not believe that this new monastic system would be created in his lifetime, but he was confident that it was necessary and would happen eventually.

\section{SHIFT FROM RITUALTO ETHICAL PRACTICE}

Vegetarianism, compassion, and non-violence: these were the practices that my participants told me characterized Jainism. Participants referred to embodied principles far more often than they did to specific rituals. Instead of hearing about different forms of puja, I was told that refraining from gossip was an important practice. Another participant discussed not using insecticides in his home. Nirmal, a PhD candidate at a nearby university, was among those who characterized described Jain practices broadly as "anything that promotes Jain values." He specified, "If walking in nature makes you think positive thoughts, then to me that's an act of Jainism. If helping your neighbor, if being in the community... anything that leads to ahimsa, aparigraha, or anekantavada to me is promoting Jainism." Responses that referred to day-to-day and ethical practices were a significant departure from what my textbooks had prepared me for; instead, the expected discussions of more ritualistic practices - such as fasting, meditation, and pujacame later, after more focused discussion and elicitation.

This is not to suggest that other more traditional practices are not still utilized, but rather to note that the range of ways in which Jains, particularly second-generation diaspora Jains, can interact with Jainism has been greatly expanded. Puja-the practice of worshipping an image of a sacred being, often the important leader Mahavira, with the intent of cultivating those qualities in oneself that the image represents-is still common at monthly meetings. Multiple participants had puja rooms in their homes, as well, but puja is not as prevalent as it is in India or as it was when the first generation immigrated. Suchit estimated that half of the JSCNC community does puja on a regular basis and that the others only do so once or twice a year on special occasions. The older members of the community were much more likely to perform puja frequently and to have favorable opinions of the practice, while the secondgeneration expressed more neutral views. Nirmal, one of the second-generation participants, understood and agreed with the goals of puja, but he does not continue the practice in his private life. He did not have any qualms about others practicing in this way, though. He commented, "If that is an effective means of reminding you [about qualities you want in yourself], then great. For me, it is not." As the second-generation teach their children about Jain practices, it seems plausible that certain traditional rituals, such as puja, will continue to diminish in importance in diaspora. In their place, Jains in America appear to be selectively adopting Western values and increasingly favoring meditation and ethical practices. The direct implication of this shift is that new practices will be adopted; my research suggests that these may well be informed and shaped by environmental and animal rights movements.

"IF WALKING IN NATURE MAKES YOU THINK
POSITIVE THOUGHTS, THEN TO ME THAT'S
AN ACT OF JAINISM. IF HELPING YOUR
NEIGHBOR, IF BEING IN THE COMMUNITY...
ANYTHING THAT LEADS TO AHIMSA,
APARIGRAHA, OR ANEKANTAVADA TO ME IS
PROMOTING JAINISM."- - Nirmal




\section{INCORPORATION OF ENVIRONMENTAL MOVEMENTS}

Religious influence relating to environmental concerns and nature often is argued to be a negative force. In Lynn White's seminal paper, "The Historical Roots of Our Ecological Crisis," he describes Christian beliefs as a direct cause of humanity's disregard for the planet. He states, "[The Christian] God planned all of this explicitly for man's benefit and rule: no item in the physical creation had any purpose save to serve man's purposes" (White 1967, 1205). By establishing humanity as above and distinct from the natural world, White sees Christianity as sowing the seeds for anthropocentricism and a use-relationship between humans and the environment. In addition to this and similar critiques of Christianity, many scholars have expressed related concerns about the world's other religious traditions, as well.

Within Jainism, there has been a strong movement in recent years to promote itself as providing a different and better narrative. In 1990, the Institute of Jainology published "The Jain Declaration on Nature." Through it, the authors sought to establish Jainism as a religion that offers an inherently ecological philosophy. This document highlighted Jain principles such as non-violence, compassion for animals, and non-possessiveness, and underscored the ways in which this tradition's core beliefs are distinct from those of many Western religions. Importantly, these beliefs include an everlasting universe with no creator and the existence of souls within all worldly entities from a human to a rock. In a more applied manner, it also made striking environmental claims, such as "the Jain faith goes one radical step further and declares unequivocally that waste and creating pollution are acts of violence" (Singhvi 1990).

The relationship between Jainism and environmentalism was a common theme in all of my research discussions with participants. Some respondents were quite enthusiastic and represented Jainism as inherently "green," while others were discouraged and frustrated at what they perceived to be a lack of sensitivity to these issues. Irrespective of their positive or negative assessments of Jainism's current environmentalist culture, all participants agreed that Jains were progressively becoming more environmentally aware and active and that this trend was strongest among the youth. In the past decade, western scholarship on Jainism has begun to address this intersection of philosophies. John Cort's essay "Green Jainism?" notes that "any Jain environmental ethic at present is at best nascent and largely unconscious and implicit" (Cort 2002, 66). Cort sees Jainism as still in the beginning stages of developing a true en- vironmental ethic. According to him, much of what already exists of this ethic is found in daily practices and as extensions of core Jain tenets, such as ahimsa and aparigraha.

However, Suchit figured among the participants who identified a firm basis for an environmental ethic within Jainism. He noted that "Scripturally, [environmentalism] has always been supported. 'Parasparopagraho Jivanam', [an important Jain teaching], means that all life is bound together in mutual cooperation." Yet, he also believed that there currently is not enough environmental effort and consideration within Jainism. He said, "Yes, the roots are there [and] very strong. In practice, [though], there has not been that much environmentalism." Providing a much more positive outlook on Jainism's "green credentials," Sujash told me that Jainism was the most environmentally friendly religion, due to the principle of aparigraha. On a number of occasions, others reiterated this view to me.

As for environmental ethics being stronger amongst the youth, many reasons were given. Nirmal told me that this was the case because of the benefit of growing up in the United States. "It doesn't just stem from the Jain principles alone, but also from growing up in a society where external actions and not just internal improvements are taken into account." He also pointed to the active environmental movements in the United States as an influence on American Jain youth. These organizations represent the welldeveloped activist culture of the United States that first-generation Jains did not experience during their formative years in India. He and others noted that when the first-generation immigrated, their concerns related to employment, education, and establishing themselves within a new country. Seen in this way, it may be understandable why environmental ethics were not primary priorities, as they are today among many second-generation Jains.

\section{SHIFTS IN DIETARY PRACTICES}

Traditionally, a Jain diet has not included meat, eggs, honey, many-seeded and root vegetables (considered to contain many single-sensed life forms), or alcohol (considered a violent drink both because of the fermentation involved and the perceived harm it causes to the body). Dairy has been acceptable, as it has traditionally been considered a holy substance (Dundas 1992, 152). This modified lacto-vegetarian diet is considered possible to maintain by all Jains-both lay and ascetic-and to be an imperative of the core principle of ahimsa. None of the adult participants in this 
research eat meat, eggs, or honey, but they do eat root vegetables and consume alcohol very occasionally. In these ways, the two youth participants eat and drink similarly to the adults, with the exception of honey; neither Nirmal nor Pranav avoid honey. My research suggests that there very well could be a new context for understanding honey which is forming within the youth, where honey has become no longer a Jain avoidance, but a vegan one. To the majority of Jain youth who are not vegans, honey may have ceased to be wholly objectionable. With regards to root vegetables, Sujash told me that while the older adult population still strictly avoids them, at a certain point "a break happened, when the older generation had their kids-[my generation] —and from that point forward these things got loose."

Veganism, the practice of avoiding the use of all non-human animals and their derived products, emerged in the United Kingdom in the middle of the nineteenth century. In historical terms, it is a very modern phenomenon, and within the Jain context, veganism has been introduced even more recently (Vegan Society 2010). Purav, a vegan, told me that he became vegan in 1993 after visiting a dairy farm (an experience and reaction which other Jain vegans also described to me), yet he thought that it wasn't until around 2000 that many Jains even became aware of veganism.

Despite the novelty of the practice, it has already attracted serious discussion and debate within diaspora Jain communities. Similar to my arguments concerning environmentalism above, participants all noted that veganism has been adopted in much larger numbers by second-generation Jains than it has by the firstgeneration. As Vallely notes, while the population of Jain vegans appears to still be small, it is significant and on the rise (Vallely 2002, 214-15). An informal survey of 1000 American Jains conducted in 2009 by Yogen Jain found that 2 percent of the firstgeneration and 11 percent of the second-generation were vegan (Pravin Shah, personal communication). While this may not constitute a scholarly quantitative survey, it does provide a rough idea of the current landscape of American Jain veganism.

At the first JSCNC event I attended, an annual campout at a local park, I ate a sandwich on my drive over. I krkew that a small percentage of Jains were vegan, but I did not expect there to be anything for me to eat. Yet, about half of the dishes provided for dinner were, in fact, vegan, and the volunteers serving the food knew exactly which dishes were and weren't suitable. I also learned that vegan options were intentionally offered at every JSCNC monthly meeting. Importantly, this level of thought and accommodation for vegans lends credence to the notion that Jain veganism is a stance adopted by more than just a few lone individuals. Moreover, this consideration for the growing population of Jain vegans appears across North America. Pranav, who has served in leadership capacities with Young Jains of America (YJA), told me that out of the roughly 800 second-generation Jains who attended the YJA conference in July 2010, over 100 identified as fully vegan. Furthermore, he said there was enough support at the weekend conference to warrant that the majority of the desserts are dairy-free and two meals are completely vegan.

Those vegan Jains who discussed their motivations for this ethical choice offered two kinds of explanations: the first appeared to come straight from Western animal rights literature, and the second directly related to core Jain values, such as ahimsa. Importantly, incorporating veganism seems to be linked to somewhat different reasons than other historical Jain dietary practices. Anne Vallely argues that "the logic [behind Jains avoiding dairy and additional animal derived foods]... is not self-control but compassion; not renunciation of the abstract and reified 'worldly experience,' but the renunciation of very tangible forms of animal exploitation" (Vallely 2004, 17). In our discussions, Rajmati provided a clear example of this. Her dietary choices were made through her own critical interpretation of Jainism, not based upon a list prescribed for her. She and her husband chose to become vegan because of the violence done to cows (a five-sensed being), but they now eat root vegetables (a one-sense being) because the relative harm is, in their view, significantly less. This opinion was standard amongst all of the vegan participants; the shift to veganism was always supported by a questioning attitude toward (rather than a wholesale acceptance of) traditional Jain dietary practices.

The trend towards veganism, while widely accepted or at least tolerated, has been a point of contention and a flashpoint for disagreement between members of Jain communities. Before moving to North Carolina and joining the JSCNC, Suchit, a vegan, was the coordinator for the pathshala in another American Jain community. While he was coordinator, he decided to show the students a film on silk production. ${ }^{9}$ This provoked a decisively negative reaction from the majority of his community members. He told me that he received "a lot of complaints from mothers that their children were asking them whether they wore silk" and "that [these sorts of films and discussions created a] negative en- 
vironment in the families." This backlash against vegan critiques appears to be commonplace. The few participants who have attempted to persuade other Jains to become vegan often expressed the sense that they were on the fringe or ignored. These feelings have led outspoken vegans such as Suchit and Purav to tone down their rhetoric, but neither has stopped trying. Purav often joked about others not listening to him, but he told me that "when the opportunity comes up, I always explain it to them...I am not going to hammer on it, [though], because people are not going to listen to it."

\section{"TODAY, [THEY] WANT TO CHANGE THE WORLD. AT 40, I WISHED THAT I COULD JUST CHANGE MY FAMILY."- Purav}

\section{DIRECTIONS}

As the second-generation ages, the trend towards veganism and the incorporation of elements of environmental and animal rights movements seems destined to continue. However, the extent to which this transformation will occur is currently unclear. While the role of traditional rituals such as puja appears to be declining in diaspora, Purav warned against expecting too great a shift in practices. He agreed that major changes were underway, but thought that the questioning attitudes of the second-generation would not always be as strong. Laughing, he speculated, "Today, [they] want to change the world. At 40, I wished that I could just change my family." These new discourses will likely face challenges once the second-generation becomes involved with careers and has families. As other priorities begin to demand more time and attention, more conservative and traditional views may regain some hold.

The lay diaspora leadership who today has assumed much power will continue to influence these important issues. In addition to leading their respective communities, these leaders also produce English-language literature. This literature can include leaders' personal views related to environmentalism, animalrights, and veganism. For example, works written by lay scholar Pravin Shah frequently include lengthy discussions of veganism that state that it is a moral imperative for Jains. ${ }^{10}$ In this way, veganism is positioned as a tenet of Jainism in educational materials that are utilized by the English speaking second-generation. The degree of influence that diaspora Jain leaders have over the representation of Jainism is currently quite strong. Yet, if a re-envisioned monastic order is established in diaspora in the future, competing power structures will likely exist. That is, if formally initiated monks and nuns start to be a part of the diaspora Jain landscape, it is unclear what role the current lay leadership would play and how much influence they would still exert. The redistribution of power could have a serious impact on the current incorporation of nontraditional practices and philosophies.

What is less clear is whether or not current diaspora changes will have an impact on practices in India. It is possible that these new practices and authority structures will remain a diaspora phenomenon, but it is seems more likely that similar discourses are already underway and will continue to develop in India, as well. As a natural extension of this research, I intend to further investigate these themes within India. 
1 One of the twenty-four enlightened teachers of Jainism, also known as a Tirthankara or Jina.

2 An enlightened soul other than an arhat

3 To ensure anonymity, participants' names have been replaced with pseudonyms in this paper.

4 Jainism is an Indian religion that presented a serious challenge to Vedic Hinduism during the middle of the first millennium BCE. It offered incisive critiques of traditional Hindu practices relating to animal sacrifice and consumption of non-vegetarian food. In contrast, Jainism promoted ahimsa (non-violence) and detailed dietary proscriptions that, among other things, forbade flesh and eggs. Its founders were the 24 tirthankaras (literally, "ford-makers"), the twenty-fourth and most recent of which was the historical figure Mahavira who lived around the same time as the Buddha.

5 In this paper, diaspora refers to Jains living outside of India, where the religion originated and most followers still live.

6 In this paper, I am using the term "youth" to represent both younger first-generation (below the age of 30) and secondgeneration Jains.

7 Jainism classifies life within a hierarchy based upon number of senses (i.e., complexity and ability to perceive pain). Singlesensed beings are those with the sense of touch, whereas five-sensed beings are those who can touch, taste, smell, hear, and see.

8 This data indicates the relative rarity of even second-generation vegan Jains, yet four of the six first-generation participants in this research were vegan, while both second-generation participants were vegetarian. It is important to note that I did not actively seek out vegan participants. It is my belief that there may be a correlation between holding a lay leadership position and identifying as vegan. Further research would be required to investigate this.

9 In captivity, once silkworms have been allowed to produce their silk cocoons, farmers "stifle"-that is, kill—the developing silk moth with prolonged exposure to temperatures of at least 110 degree Celsius, in order to prevent the moth from emerging and harming the cocoons (Franck 2001, 17).

10 A representative appeal, written by Pravin Shah, can be found on the JAINA (Jain Associations in North America) website: http://www.jaina.org/blogpost/258456/109257/A-Thought-for-Paryushan-by-Pravin-Shah 


\section{BIBLIOGRAPHY}

Babb, Lawrence.1996. Absent Lord: Ascetics and Kings in a Jain Ritual Culture. Berkeley: University of California Press.

Cort, John E. 1991. "The Svetambar Murtipujak Jain Mendicant." Royal Anthropological Institute of Great Britain and Ireland 651-71.

—. 2002. "Green Jainism? Notes and Queries towards a Possible Jain Environmental Ethic." In Jainism and Ecology: Nonviolence in the Web of Life, edited by Christopher Chapple, 63-94. Cambridge: Harvard University Press.

Dundas, Paul. 1992. The Jains. New York: Routledge.

Franck, Robert. 2001. Silk, Mohair, Cashmere and Other Luxury Fibres. Boca Raton: Woodhead Publishing.

Jain, Andrea R., and Jeffrey J. Kripal. 2009. “Quietism and Karma: Non-Action as Non-Ethics in Jain Asceticism." Common Knowledge, 197-207.

Jaini, Padmanabh S. 1991. Gender and Salvation: Jaina Debates on the Spiritual Liberation of Women. Berkeley: University of California Press.

Laidlaw, James. 2005. "A Life Worth Leaving: Fasting to Death as Telos of a Jain Religious Life." Economy and Society, 178-99.

—. 2010. "Ethical Traditions in Question: Diaspora Jainism and the Environmental and Animal Liberation Movements." In Ethical Life in South Asia, edited by Anand Pandian and Daud Ali, 61-80. Bloomington: Indiana University Press.

Long, Jeffrey. 2009. Jainism: An Introduction. New York: I.B. Tauris.

Singhvi, L.M. 1990. Jain Declaration of Nature. http://www.jainology.org/publications/jaindelaration-on-nature/ (accessed April 2, 2011).

The Vegan Society. 2010. History of the Society. http://www.vegansociety.com/about/history.aspx (accessed February 19, 2011).

Vallely, Anne. 2002. "From Liberation to Ecology: Ethical Discourses among Orthodox and Diaspora Jains." In Jainism and Ecology: Nonviolence in the Web of Life, edited by Christopher Chapple, 193-213. Cambridge: Harvard University Press.

This work is licensed under a Creative Commons AttributionNonCommercialNoDerivs 3.0 Unported License.

-. 2004. "The Jain Plate: The Semiotics of the Diaspora Diet." In South Asians in the Diaspora: Histories and Religious Traditions, edited by Knut Jacobsen and Pratap Kumar, 3-22. Boston: Brill.

White, Lynn. 1967. “The Historical Roots of our Ecological Crisis.” Science, 1203-7. 